Derek Hudson has taken full advantage of his opportunities. His biography is warm and sympathetic, written with insight and understanding, and executed handsomely in the finest Rackham tradition. As the only definitive biography of Rackham that has been published, it is of great significance because, by showing the enormous productivity of the man, it releases its readers from the tendency to judge him solely on the basis of the few favorite works that happen to linger in memory. Moreover, although it reveals the decision of a fine genius to reach for a limitless audience through publication, it also shows how he defeated the restrictions of the colorplate process as it existed in his time by unswerving insistence on the highest possible standards of workmanship.

Mr. Hudson reproduces many of Rackham's originals, some of which have never before seen publication. Regrettably this is done too of ten without normal credit linescertain plates, for example, are from originals that have been in the Columbia collection for some time, without notice to that effect or to previous ownership. While we are on the subject of faults, one that will cause quite general annoyance is the lack of an index.

Mr. Bertram Rota has added a check-list of "The Printed Work of Arthur Rackham" which brings his bibliography up to date. This will be gladly received by librarians and collectors, because the definitive treatment by Latimore and Haskell has been out of print for many years. Mr. Rota, furthermore, has made substantial additions to the Rackham canon-at least sixteen unrecorded volumes as well as a great many magazine issues. His form of listing is highly abbreviated; while this facilitates checking, more detailed information about the hitherto unrecorded works would have been welcome. The list is available in separate form through Bodley House, Vigo Street, London W. 1.Roland Baughman, Columbia University.

\section{Studies in Microforms}

Full-Size Photocopying. By William R. Hawken. (The State of the Library Art, Volume V, Part 3) New Brunswick, N. J.:
Graduate School of Library Service, Rutgers, The State University, 1960. 397p. $\$ 8.00$.

This title completes the section on "Reproduction of Materials" from a series of studies covering most of the technical as pects of librarianship. The two earlier reports on the micro-forms, which make up the rest of the section, have been reviewed before. ${ }^{1}$ This volume supplements them admirably and should be used in conjunction with them. The line separating microcopying from full-size photocopying is rapidly becoming fainter, and one must understand the techniques of one in order to apply the other.

Chapters are entitled: "Photostat (used here as a generic term), Stabilization Processes, Photronic Reproduction, Verifax, Diffusion Transfer Process, Diazo, Thermography, Photothermography (Kalfax), Xerography, Electrofax, and the Electrolytic Process (3M Filmac)." "Each chapter may be studied as an independent unit, since it concludes with its own bibliography. This study by units would have been made a little easier if the running heads at the tops of the pages had been by main title and chapter title, rather than series title and main title. The chapters on "Xerography" (83 pp.), "Diazo" (77 pp.) and "Photostat" (59 pp.) are the longest; and each one could be used as an introductory handbook for its process with the addition of a few more illustrations. A criticism aimed at the two volumes on microforms was that they should have been illustrated. This volume is, but the few included tend to whet one's appetite for more. One feels that the author would have included more if the economic restrictions of publication had permitted.

This series of studies is intended to provide "a survey of the published and unpublished literature of each facet of the field." This has been done in this volume, as in the other two. Being published later than they, it contains bibliographic references through 1958, and a few into 1959. The form adapted from the series has resulted in three volumes that are excellent reference tools and basic guides to the literature of photoduplication. It has not resulted in

1 Hubbard W. Ballou, "Studies in Microforms," $C R L$, XXI (1960). 494.495. 
texts that read easily. This reviewer hopes that it may be possible for each of the authors (Hawkins, Stewart, and Hawken) to write further on their respective subjects, unfettered by the editorial restrictions that appear to be compressing them into a series pattern. A minor, but annoying result of this approach, is the fact that the author's name does not appear on the spine of the book, so that one has to remember that volume three is Hawken on Full-Size Photocopying.

Guide to Microforms in Print, 1961. Edited by Albert James Diaz. Washington, D. C.: Microcard Editions, Inc., 1961. 72p. $\$ 4.00$.

On a shelf within arm's reach of my desk there is a short row of about a dozen small catalogs listing the products of the largest producers of published microforms. I have occasion to refer to these daily, both in a positive sense ("Where can I get such-andsuch a microform?") or in a negative sense ("Do we have to film so-and-so, or has someone else already done it?"). When I refer to them, I usually have to look at each catalog, and their arrangements differ just enough to throw one out of rhythm.

Within this one-volume guide, I now have everything on my reference shelf, plus a number of other catalogs that $I$ had not happened to lay my hands on. Included are forty-two publishers of microforms, and the listings are arranged in a single alphabet. Items are listed in uniform manner, with the basic information given in a reasonably abbreviated form (i.e. author, title, date, price, publisher, and type of microform). There are just over ten thousand lines of entries, most of them one line long. The book has been printed through use of the Compos-o-line sequential card camera, so that it should not be too great a job for the publisher to keep it up-to-date.

This is not a union list of microforms. It is a listing of microform publications offered for sale on a regular basis. Some non-commercial producers (e.g. New York Public Library, National Archives) are included. Theses, dissertations, and Xerox Copyflo enlargements from microfilm are not listed. One surprising omission is the A. C. R. L. Microcard Series published by the University of Rochester Press (which is listed). Each publisher is identified by an alphabetic abbreviation. It is too bad that it was decided to set up a new system of abbreviations, rather than establish an extension of the familiar ones found in the Union List of Serials.

For those who might want to carry this useful tool in a shirt pocket and refer to it with the Microcard hand viewer, there is included on the back cover a Microcard copy of the whole list. This is accomplished on two double-faced Microcards. It seems almost certain that this volume will meet with enough approval to ensure its becoming an annual publication.

Microcopies on Gevaert Duplofilms. New York, The Gevaert Co. of America, Inc., n.d. 28p. On request.

Basic Microfilm Indexing and Filing Techniques. Mt. Prospect, Ill.: Charles Bruning Co., Inc., 1959. 20p. On request.

There are times when one wants a booklet (preferably free) spelling out the basic principles of microfilming to put into the hands of a person who has asked questions about microfilming. This should give him something to look at before one begins to tell him about the problems that are involved in his particular application. This booklet should be one step more elementary than the Kodak data books on Copying and Microfilming.

Gevaert has for some time had such a booklet, printed in Belgium (an edition in French and one in English), and well illustrated. The first half of it was just the thing to fill the requirements listed above. The second half went into more complete technical details about Gevaert microcopying materials. There is now an edition printed in the United States that is almost as complete as the Belgian edition. It will serve to take the place of a "First Steps in Microfilming" until such a title comes along.

Another aspect of microfilming that is confusing concerns the many details involved in indexing a large file of documents for microfilming. Remington Rand and Recordak have published booklets about this subject, and now Bruning has joined the parade with this well illustrated little volume 
which carries a wealth of information in an easily accessible form.

O P, March 1961 Supplement. Ann Arbor, Mich.; University Microfilms, Inc., [1961]. 62 p. On request.

The O-P program which was initiated in 1958 by University Microfilms has been one of the most interesting developments in photoduplication to appear since microfilm came over the horizon. Through its wedding of microfilm with full-sized photocopy, it has made use of the best features of each process. Its growth has been nothing short of phenomenal, resulting in University Microfilm's becoming a publisher (re-publisher?) with a list longer than that of any other commercial firm in this country.

Most of us first learned about the program from a short note entitled "Microxerobook" in the New York Times, Book Review Section of March 30, 1958. A fuller description appeared in the second issue of volume four of Microcosm in April of the same year. In the next issue of that newsletter appeared the first listing of titles available. This ran to about one hundred twentyfive entries and included the names of forty-three cooperating publishers.

Since then, five lists have come out as separate catalogs. The first four were cumulative lists, appearing in January 1959, June 1959. August 1959 and January 1960. The latest list is a supplement, carrying the project up to March 1961. The growth of the program is shown by their contents: $1 / 59$-ca. 500 listings and 52 publishers, 6/59-ca. 1200 listings and 98 publishers, 8/59-ca. 1400 listings and 101 publishers, 1/60-ca. 2100 listings and 110 publishers. The last list brings the number up to just about 4000 titles from 134 publishers.

This latest catalog is a handsome booklet, well printed in a legible type, and with an attractive cover. Unfortunately, it is a different size from the January 1960 list which it supplements. As an indication of present trends of interest, there is a separate six page listing of titles in the Russian language. These 220 items are listed alphabetically both in the main section and in the separate section. Listings are by: author, title, place of publication, publisher, date, O-P number, and price. These O-P catalogs do not include all the resources of University Microfilms; they note only those titles on their O-P Books project. Much of the material in the other projects of this company (e.g. doctoral dissertations, STC project, etc.) is also available as xerographic enlargements from microfilm.

\section{Proceedings of the Ninth Annual Meeting and Convention Held At New York, April, 1960. Edited by Vernon D. Tate. Annap- olis, Md.: National Microfilm Association, 1960. 257p. $\$ 8.00$.}

The second annual meeting of the $\mathrm{Na}$ tional Microfilm Association was held in New York in 1953, took two days, and had a registration of just under two hundred. The ninth meeting was again in New York in 1960 , covered three days, and had a registration of close to one thousand. The proceedings of the second meeting were issued in a mimeographed volume of seventy-four pages, whereas those of the ninth are a well printed volume of more than three times that length. Most of the papers at the second meeting had information of value to librarians concerned with microfilm. At the ninth meeting there was much of interest to librarians and archivists in the four general sessions, and a special session of eight papers was prepared for them.

The first general session was devoted to the tools of microfilming. Reports were submitted by: Photo Devices, Recordak, Photostat, Griscombe, Bruning, Prestoseal, Keuffel \& Esser, Microcard and Xerox. Each speaker outlined briefly what new equipment his company had to offer since the previous year.

Just as most academic and industrial research is now tied in with government sponsored projects, so also one finds most large microfilming programs associated with government orders. A special session (which ran concurrently with the library program) was devoted to the Department of Defense specifications for microfilming. These papers dealt with the attempts to standardize equipment, supplies, and techniques used for government contract work, so that all projects could be synchronized with each other. Indirectly, the outgrowth of this work will have a bearing on library microfilming. 
Technology was the subject of the next session. Papers were read on subjects ranging from present day problems of insert cards used on IBM equipment, to speculations on future applications of computor-film, tapefilm, and fiber optics used for scanning film. There was enough "cloud nine" thinking to make one realize that the field of microphotography is not static.

Another session was given to the applications of microfilming. These covered subjects from a number of fields including one that was sub terra and one sub rosa. The former was a suggestion that municipal water and sewage works microfilm their charts and records so that the men who go beneath the streets could carry hand viewers to examine their maps on the job. The latter told about the use of microfilm by the O. S. S. during the second world war.

The final section of this volume is devoted to the library-archive session. Papers were read about the New York Public Library which has been microfilming for over twenty five years, and the University of Michigan Library which began to do so just over five years ago. Microfilm was credited with giving historians a new tool for research, it was blamed for the headaches that it gives cataloguers in libraries, and it was shown that it could make an out-of-print book in-print and thus confuse the compilors of listings. Although librarians account for only a small part of the membership of the association, it has been gratifying to note the increase in the attendance of librarians at the annual meetings and the subsequent recognition accorded their problems by the association.- Hubbard W. Ballou, Columbia University.

The United States Military Academy Library at West Point, N. Y., won the John Cotton Dana Award among college and university libraries for a publicity program showing how the library relates itself to the life of the whole organization. The contest is jointly sponsored by the Wilson Library Bulletin and the Public Relations Section of ALA. Scrapbooks from many kinds of libraries all over the country are the basis for which the awards are granted. The winning scrapbooks are available on loan from the library of the ALA at Chicago.

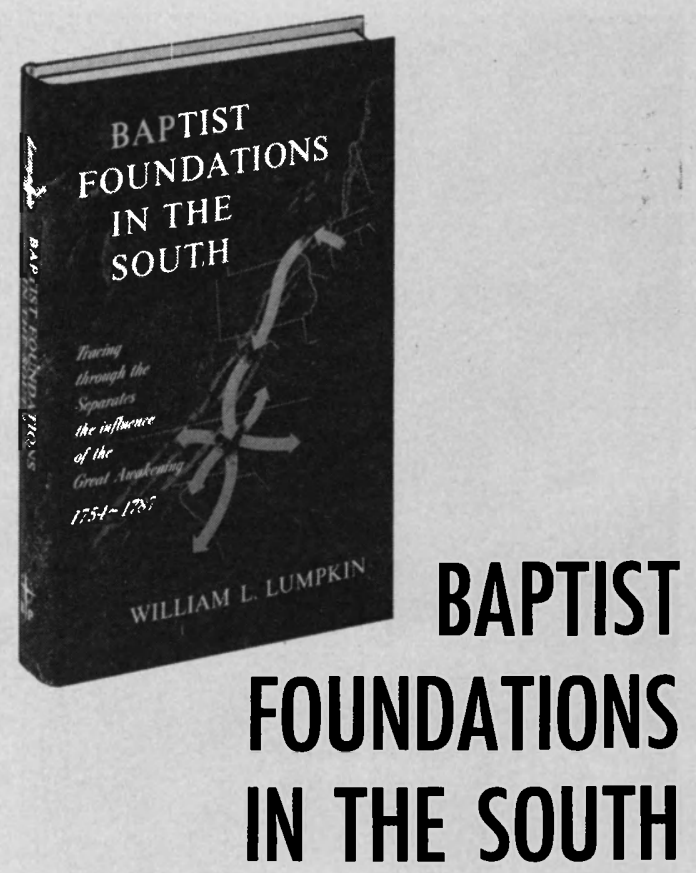

\section{William L. Lumpkin}

The exciting story of a phase in American church history that has never before been adequately treated ... the influence of the Separates on Baptists in the South (1754-1787). A valuable historical and reference volume.

$\$ 4.25$

\section{Chapter titles:}

- Separatism in Connecticut

- Thrust Forth and Entering In

- The Promised Land: Its Posession Begun

- Brush Fires in All Directions

- Are They Blood Brothers?

- Persecution and Exodus

- All Ablaze in Virginia

- Struggle for Freedom in Virginia

- Claiming the Frontier

- Post-Revolutionary Revival and Merger

- Significance of the Movement

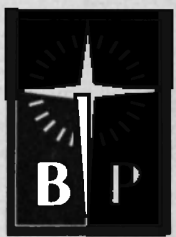

BROADMAN PRESS

Nashville 3, Tennessee 